\title{
EL VALOR EPISTÉMICO DE LAS BUENAS COMPAÑÍAS
}

\author{
Ramón Vargas-Machuca Ortega \\ Universidad de Cádiz
}

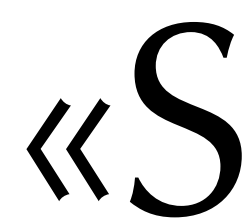

on muy pocos los filósofos españoles que, sin pertenecer al gremio de los iusfilósofos, se hayan interesado por el Derecho. Y es verdaderamente sorprendente la ignorancia que nuestros científicos sociales, cultivadores de las humanidades, etc., suelen exhibir a propósito de la cultura jurídica» ${ }^{1}$. Comparto esta opinión de $\mathrm{Ma}$ nuel ATIENZA expresada en un libro colectivo de homenaje a la figura de Javier MUGUERZA, quien también en este asunto iba a contracorriente de la mayoría. Emulando en este aspecto a Javier y a diferencia de buena parte de mis colegas, mi interés por la filosofía del derecho ha ido en aumento. No hace mucho testimoniaba mi gratitud a quien a lo largo de estos años me ha aportado bastantes razones para sentirme cercano a este campo del saber, sobre todo, al modo como la mayoría de los miembros de este departamento y allegados lo vienen cultivando. «Francisco LAPORTA, decía, me ha ayudado a descubrir algo crucial: que no podía seguir ejerciendo de "filósofo práctico" de la política sin la compañía de una buena Teoría del Derecho» ${ }^{2}$. En esta ocasión tengo la oportunidad de hacer extensivo el agradecimiento a Liborio HIERRO y explicar los motivos.

Nada hubiera sido igual al respecto sin contar con la amistad de Elías DíAz. Pronto me hizo interiorizar, como si de una ley moral se tratara, que la relación entre Estado de Derecho y Democracia es inescindible. Y como su ejemplo empujaba, uno podía enfrentarse a las trampas a la legalidad perpetradas o consentidas por «los nuestros» al precio de sentirnos casi en minoría de a uno en foros políticos donde solo funciona la adhesión o en su defecto la trifulca deplorable, como hemos comprobado recientemente. Por otra parte, su singular modo de «crear escuela», que propiciaba gran libertad de investigación, rendimientos de excelencia y relaciones personales envidiables, me permitió disfrutar del clima intelectual que él alentaba entre los miembros de su departamento y allegados. Junto a MUGUERZA fue artífice de un espacio institucional compartido en la que la filosofía moral y la filosofía jurídica estuvieron tan unidas de hecho como lo están teóricamente en cualquier reflexión filosófica seria. Y aunque en términos institucionales aquel proyecto duró poco, algunos sí mantuvimos cierta comunidad de pensamiento y unas buenas relaciones.

\footnotetext{
1 «La filosofía del derecho de Javier Muguerza», en Diálogos con Javier Muguerza. Paisajes para una exposición virtual, Isegoría, julio 2016, 339.

2 «Democracia y verdad», Tomando en serio la Teoría Política, I. WEnCES (ed.), CEPC, 2015, 291.
} 
Claro que ni la amistad, admiración y gratitud me acreditan para compartir tribuna con expertos tan solventes en las ciencias jurídicas como los que participan en este homenaje. Entre otras razones, porque no soy experto en cosa alguna. Uno trata de ejercer de filósofo práctico; y cuando se viene arriba, a esta manera de pensar le llama «saber político», probablemente recordando a inspiradores de juventud como GRAMSCI o el filósofo Manuel SACRISTÁN. Se trata de pensar la política echando mano del recurso de la reflexividad en la senda de la tradición ilustrada; pero también, de pensar políticamente en tanto uno se siente participante, no ajeno al funcionamiento de este ámbito de lo social. De esta disposición puede resultar una destreza metacognitiva de la que al menos cabe esperar una cosa: que la especulación, el debate o el juicio políticos sean algo más respetables y mejor informados.

Para desempeñar esta tarea es preferible la diversidad cognitiva: echar mano de la «caja de herramientas» de las ciencias sociales, merodear en la frontera de distintos saberes y articular información de diferente procedencia. De esta manera se puede adquirir una visión más inclusiva y de mayor alcance sobre los asuntos; también permite ser más precavido a la hora de ponderar y jerarquizar retos ${ }^{3}$. Y puesto que la configuración institucional de la política determina hasta cierto punto la calidad moral y la eficacia de toda ejecutoria política, la vecindad con la mejor Teoría del Derecho resulta imprescindible. De lo contrario, esta sabiduría práctica, casi artesanal como apunta Félix OvejERO, se hace simplista y acaba en cháchara, sermón, tertulia o argumentario.

Este punto de vista se sostiene en unos cuantos supuestos que comparto con los dos homenajeados: el conocimiento experto es un componente necesario del sistema de decisiones políticas y por ello de las relaciones de poder. Dado que ni la voluntad colectiva es omnisciente ni los expertos, desinteresados, conviene fijar un deslinde claro entre las esferas del saber y el poder. Por eso y frente a las formulaciones tecnocráticas o frente al recurso populista, vía de escape al resentimiento producido por las élites, prevalece la convicción de que el buen funcionamiento de una democracia representativa en el marco de un Estado de Derecho legitima y mejora a veces las decisiones de la comunidad política constituida.

Pero en las relaciones entre conocimiento y política no basta confiarlo todo a los procedimientos. Aunque sean los más verosímiles y menos injustos, son imperfectos, no producen necesariamente verdad ni justicia; a lo sumo, certifican que se han hecho las cosas de la manera más o menos correcta. Además, en la filosofía práctica entendida de la manera indicada arriba, el conocimiento que se precisa se obtiene en buena parte «de segunda mano». Teniendo en cuenta las enmarañadas imperfecciones de las ciencias sociales y entornos cada vez más complejos y cambiantes así como encrucijadas de decisión conflictivas desde el punto de vista moral, político y jurídico, se termina concluyendo que cuenta y mucho la fiabilidad personal. Por eso, quienes en el escenario público ofician como expertos, decisores u opinantes deben estar pertrechados de ciertos rasgos de la personalidad: solvencia en su campo, amor a la verdad, imparcialidad, apertura de miras, ausencia de dogmatismos, cierta coherencia moral y sentido de la responsabilidad. Justamente por estar equipados con estas y otras virtudes epistémicas y morales, Liborio y Paco me han parecido siempre individuos creíbles y fiables;

\footnotetext{
${ }^{3}$ P. TetLock, El juicio político de los expertos, Madrid, Capitán Swing, 28-29.
} 
personas cabales que ayudan a pensar correctamente, formar opiniones razonables y configurar arquitecturas de decisión para actuar con rectitud y prudencia. En mi caso, muchos de sus escritos han representad un aporte de controles de calidad en el ejercicio de la especulación política.

LAPORTA ayuda y mucho con sus artículos de opinión a desenmascarar a ese género tan abundante de expresiones-trampas, cuya sola formulación pretende abortar toda discusión sobre el sentido apropiado de las palabras y su alcance real. Por ejemplo, lo ha logrado con la estafa retórica del «derecho a decidir» o la añoranza de un «poder constituyente», deseo encubierto de una supremacía fáctica, un momento amorfo y sin reglas que propicie el despliegue de una voluntad política sin controles reglados. Hace pocos días volvía a la carga en el diario El País (31 de octubre de 2016) contra las supuestas excelencias de la democracia de referéndum y espigaba algunos de los muchos y buenos argumentos que in extenso había desarrollado en un excelente trabajo sobre la representación (Doxa, núm. 6, 1989). También he disfrutado de la conversación inteligente y lúcida que ambos propician, de su capacidad analítica e ironía, más contenida en Liborio y rotunda en Paco. Se agradece un estilo comunicacional tan ajeno a esa petulancia insufrible y no infrecuente en tantos expertos de postín. En fin, con ellos uno sabe que está en buena compañía.

Si bien lo que sigue es para muchos de Vds. lección sabida, no parece serlo ni para buena parte de los «filósofos morales» ni para muchos politólogos y «analistas» que se prodigan en la escena pública; tampoco, para los actores principales de la vieja o de la nueva política. Señalo dos o tres asuntos clave en los que los profesores LAPORTA e HIERRO se han esmerado prestando un gran servicio al desarrollo y difusión del conocimiento de la Teoría del Derecho y de la Filosofía moral y política. Buena ocasión es esta para recodarlo y reconocerlo. Y si sus indicaciones se hubieran interiorizado como saber político y saber ciudadano, «otro gallo nos cantaría». El libro de LAPORTA El imperio de la ley. Una visión actual (Trotta, 2007) es una joya. Mucho se puede aprender en sus páginas. Resalto aquí algunos de sus logros. En el arranque del libro se despliega una potente fundamentación del principio de la autonomía moral. Vinculada a la racionalidad como condición del agente moral es inseparable de la dignidad de las personas, respeto e igual trato que cada una de ellas merece. Estas credenciales que nos constituyen como agentes morales representan una condición de la que se participa distributivamente (no como un rasgo genérico); la condición de ser fin en sí mismo y nunca solo un medio para fines particulares se usufructúa individualmente. Se trata, pues, de un principio universalizable que funciona como ideal regulativo, no único pero sí básico de la justicia. La autonomía moral así entendida es un fin en sí que satisface exigencias insustituibles de justicia y controles de racionalidad que legitiman su primacía.

De otro lado y en un país poco cuidadoso con las formas, LAPORTA insiste en el valor moral de los aspectos formales de un buen principio y una buena regla. Subraya algunas propiedades necesarias de los principios éticos, entre ellas, la congruencia epistémica. Gracias a herramientas analíticas y de crítica racional y teniendo en cuenta la información empírica apropiada, los principios no solo son deferentes con criterios de consistencia lógica o coherencia sino que ayudan a detectar los prejuicios y ponerlos en su sitio. Con esta dotación, los principios contribuyen a que no se adultere la relación entre ética 
y política. Por su parte, las reglas jurídicas representan el tipo de normas que mejor se ajustan a las pretensiones de la política como orden. Un elemental sentido de la decencia y la autoestima debería incitar a los actores políticos al respeto de las propiedades y requisitos formales que definen, distinguen y permiten reconocer a las reglas como tales.

Una norma jurídica acorde con sus exigencias formales y materiales confiere a la vida en común una dimensión ética no intercambiable por otro tipo de norma alternativa. En mas de una ocasión lo ha recordado LAPORTA señalando algunas valiosas exigencias de las reglas jurídicas: que sean concluyentes y perentorias; que el poder solo se ejerza por quien esté facultado para ello mediante una regla de competencia; que el poder de crear las normas esté separado del poder de aquel que las aplica; o que la lógica de la justificación proceda de modo que las acciones se justifiquen apelando a las reglas y estas apelando a los principios. Estos y otros criterios análogos tomados en serio aportan previsibilidad, seguridad y algunas certezas en un mar de incertidumbre como el de la interacción colectiva. Actuar de acuerdo con esas pautas de corrección resultan constricciones indispensable para una relación adecuada con otros ingredientes normativos de la moral y la política, ya sean proyectos de vida buena, programas o estrategias.

De la obra de Liborio HiERRO destaco su trabajo, «El concepto de justicia y la teoría de los derechos» [en Elías DíAz y José L. Colomer (eds.), Estado, justicia, derechos, Alianza, 2002: 11-73]. A propósito de las relaciones entre teoría de la justicia y democracia, este y otros trabajos suyos relacionados han aportado una razonable salida a quienes no sabíamos escapar del laberinto hermenéutico que nos traía y llevaba de RAWLS y sus seguidores a la cohorte de los que con él polemizaban. No obstante, algunos pensábamos que una buena filosofía (para la) práctica no debe limitarse a justificar buenos principios sino que debe configurarlos de tal modo que los convierta en motivadores de la acción; que debe además diseñar una conjunción de recursos normativos de distinta naturaleza y rango para tratar de domar el uso del poder y hacerlo valioso y merecedor del consentimiento y obediencia. En suma, una concepción de la justicia con estas pretensiones tiene que ir acompañada de una teoría de la autoridad que de una manera consecuente con aquella determine: quién debe hacer qué y por qué en el seno de una comunidad política constituida.

Liborio da cumplimiento a este propósito y desarrolla con la parsimonia requerida buenos argumentos para justificar la interdependencia entre: un principio de justicia, básico e insustituible, el de autonomía moral entendido en un sentido muy similar al de LAPORTA; el criterio de distribución que de ese principio se deduce (reparto el igual y necesario del repertorio de los derechos humanos (un conjunto de bienes primarios, condición necesaria para el desarrollo de las capacidades de la personalidad moral y medio omnivalente para una gama amplia de fines últimos); y un procedimiento de distribución o autoridad facultada para aplicar de la mejor manera disponible aquel criterio de reparto. Esto último lo aporta el correcto funcionamiento de la democracia en el marco de un orden legal constituido.

La legitimidad y corrección de la democracia como procedimiento de distribución se justifica por dos rasgos que incluye el modelo de democracia constitucional: hacer realidad el principio moral de la autonomía en el ejercicio de la participación política; y gracias a su dimensión de Estado de Derecho, otorgar especial protección legal a los derechos fundamentales en su condición de criterio irreemplazable de justicia y 
garantizar su provisión al conjunto de los ciudadanos. Y resume esta conexión moral y política de esta manera tan expresiva: «ni un gobierno está justificado, aunque garantice los derechos, si no es consentido; ni un gobierno está justificado, aunque sea consentido, si no garantiza los derechos» (p. 29).

En la teoría de Liborio importa qué se decide y cómo; pero también lo que resulta. Si aspiramos a promover la autonomía moral, debemos calibrar qué resultados del funcionamiento de aquella logran que cada vez más personas puedan actuar de modo autónomo y desenvolverse como persona moral. Si la extensión real de la autonomía moral importa, la eficiencia, dice, hace su incómoda aparición. A su juicio, la teoría de la justicia no pueda limitarse a fijar los requisitos del procedimiento; tiene que dar cabida, además, a las cuestiones relativas a la producción y distribución de los bienes y recursos que permiten a los seres humanos desarrollarse como agentes morales en un contexto social dado. Ello conlleva determinar el lugar que debe ocupar la eficiencia en una teoría de la justicia como la que él desarrolla.

En primer lugar, la pretensión de neutralidad de una teoría eficientista de la elección sociales es falaz e inviable; tanto como la neutralidad que se arroga la teoría procedimental de la justicia. Ambas construcciones tienen una fuerte impronta normativa. La estrategia procedimentalista supone algún fundamento último en una concepción de la persona, a la postre una cierta concepción del bien, que opera como principio independiente y externo del que trae razón el procedimiento. Por su parte, el «eficientismo» de la economía política al uso implica una particular concepción de la justicia que permite a sus promotores justificar sus decisiones y evaluar las consecuencias que producen. Liborio asume el reto de incorporar a su teoría de los derechos, en tanto que concepción substantiva de la justicia, el concepto de eficiencia como ingrediente necesario pero instrumental para el logro de resultados de justicia. La compatibilidad entre racionalidad económica como parámetro de decisión social - la eficiencia entendida como maximización de la riqueza social al modo de la economía del bienestar- y las exigencias de la justicia como teoría de los derechos se produce si el incremento de la producción admite una distribución igualitaria de los recursos y proporcional a las carencias de satisfacción de las necesidades básicas de cada uno (Justicia, igualdad y eficiencia. Centro de Estudios Políticos y Constitucionales, 2002). A partir del examen de las objeciones de DwORKIN al «análisis económico del Derecho» y Richard POSNER, Liborio HIERRO despliega en este y otros ensayos una informada e ilustrativa argumentación sobre el asunto. También proporciona mejores razones para una intención socialdemócrata que hemos compartido en momentos de esperanza y otros más aciagos que parecen retornar ahora.

Termino reconociendo que gozar de la amistad de ambos a lo largo de estos años ha sido un regalo. Ellos no han influido en lo que pienso pero sí en como pienso; les agradezco sobre todo que me hayan ayudado a pensar correctamente. Salud y suerte para ellos; que perdure su talento y continúe la conversación. 